\title{
ARTIKEL
}

\section{Het verhaal van/in de narratieve criminologie}

\author{
Olga Petintseva \& Martina Althoff
}

Criminologen kijken wel vaker over het hekje bij collega's uit andere disciplines, om nieuwe trends en inzichten vervolgens te vertalen naar criminologisch relevante thema's, hierbij rekening houdend met de domeinspecifieke nuances en gevoeligheden. Het was weliswaar lang wachten vooraleer een van de belangrijke shifts binnen de sociale wetenschappen - met name de narrative turn van de jaren 1970 (zie bijv. het themanummer van Critical Inquiry in 1979 en de invloedrijke collectie On narrative met baanbrekende inzichten over de rol van narratieven) weerklank vond binnen de criminologie (Maruna, 2015; Presser, 2016).

Het centraal stellen van de betekenis van het talige in de context van criminaliteit is niet nieuw, maar is geëvolueerd met de opkomst van het interpretatieve paradigma in de criminologie sinds de jaren 1950. Het symbolisch interactionisme en de etnomethodologie benadrukken dat menselijke handelingen altijd plaatsvinden binnen sociale netwerken van betekenis die onderhandeld moeten worden en dus veranderlijk zijn. Taal speelt een sleutelrol in dit circulaire interactieve proces. Ook zijn er prominente werken binnen de rechtssociologie en de rechtspsychologie die een vruchtbare toepassing van het narratief perspectief demonstreren. Denk bijvoorbeeld aan de prominente studie van Ewick en Silbey (1995) over de relatie tussen subversieve en hegemoniale rechtsverhalen, of de studies van rechtspsychologen over rechterlijke uitspraken als storytelling. Criminologen wier werk als baanbrekend wordt beschouwd werkten ook al decennialang rond verhalen: de narratieven van daders werden bijvoorbeeld gecentraliseerd door de Chicago School-onderzoekers, door Gresham Sykes en David Matza, evenals door Jack Katz. Feministische criminologen voerden aan dat primaire ervaringen en eerstepersoonverhalen van vrouwen die slachtoffer werden van seksueel geweld op de voorgrond moeten staan. Narratieven kregen ook een prominente plaats in het streven naar meer participatieve modellen van (straf)rechtsbedeling (Van Swaaningen, 1997). René Foqué en Just 't Hart hebben de term 'narratieve kennis' in hun klassieker Instrumentaliteit en Rechtsbescherming: Grondslagen van een Strafrechtelijke Waardendiscussie (1990) vooral gekoppeld aan de romanliteratuur, maar ze hebben dit nadrukkelijk doordacht in de zin van Habermas' Herrschaftsfreier Diskurs' en Michel Foucaults ideeën over het 'verworpen weten' dat paradigmawisselingen initieert. Ook recenter hadden de existentiële criminologie (Crewe \& Lippens, 2009), dispositionele theorie, culturele criminologie ${ }^{1}$ en ver-

\footnotetext{
* Met dank aan René van Swaaningen voor de tip over Nederlandstalige narratieve benaderingen avant la lettre.

1 Hoewel narratief als specifieke discursieve vorm ondergeschikt bleef binnen culturele criminologie (Petintseva, 2015).
} 
schillende individuele onderzoekers hier oog voor (bijv. Maruna, 2001). Toch was het pas eind de jaren '00 dat de narratieve criminologie zich begon te bestendigen als een volwaardige stroming. Vooral het artikel van Lois Presser (2009), 'The narratives of offenders', dat verscheen in Theoretical Criminology, zette een en ander in gang. Deze stroming is geïnspireerd door de narratieve psychologie, het cultureel structuralisme en het postmodernisme, en ze legt uitdrukkelijk links naar de criminologische tradities van culturele criminologie (Aspden \& Hayward, 2015; Brisman in dit themanummer; Ferrell, Hayward \& Young, 2015; Mills \& Fleetwood, 2019) en constitutieve criminologie (Henry \& Milovanovic, 1997) (voor een meer gedetailleerde uiteenzetting over de ontstaanscontext van de narratieve criminologie zie Sandberg \& Ugelvik, 2016).

Narratieve criminologen 'focussen' niet alleen op narratieven en/of hanteren narratieve methoden (van analyse), hun theoretische kernbijdrage zit in de opvatting van narratieven als constitutief voor acties (ongeacht hun waarheidsgehalte) (Presser, 2009; Sandberg, 2010). Deze onderzoekers staan namelijk stil bij hoe narratieven schadelijke handelingen inspireren en drijven of juist mensen hiervan weerhouden. Ze stellen zich eveneens de vraag welke narratieven ertoe bijdragen dat mensen harm legitimeren of negeren of hoe narratieven aangewend worden om hieraan betekenis/verklaring te geven (Presser \& Sandberg 2015a; Presser, 2018). Narratieven kunnen met name een script opleveren dat suggereert welke acties passend zijn (bijv. geweld) in welke context en voor/door wie (Stein, 2020). Narratieve criminologen spreken dan ook van sociale werkelijkheid als inherent storied en van de mens als homo narrativus. Daar hoort een gewaagde stelling bij: 'Narrated experience is the only kind there is. We live in the narrated world; we liberate ourselves from one story only to enter another' (Presser \& Sandberg, 2015 b, p. 289). Narratieven geven volgens deze academici vorm aan de realiteit in plaats van deze louter te weerspiegelen, of puur een perceptie van de werkelijkheid weer te geven. Narratieven in deze invulling zijn evenmin gelijk te stellen aan post-factum rationaliseringen van schadelijke gedragingen zoals Sykes en Matza (1957) met hun neutraliseringstechnieken poneerden, want: 'Narrative criminology conceives of a world where experience is always storied and where action advances or realizes the story' (Presser \& Sandberg 2015b: 287, onderstreping zelf aangebracht). Uiteindelijk wordt met dit perspectief de bestaande aandacht voor narratieven over deviant gedrag tot centrale onderzoekfocus verheven en theoretisch geconceptualiseerd.

\section{Levendige discussies aangaande de basispremissen over narratieven}

Het narratief is een specifieke discursieve vorm die een opeenvolging van gebeurtenissen of ervaringen gedurende een tijd volgt om vervolgens een moreel transcendent punt te maken (bijvoorbeeld een bepaalde identiteit te construeren of een evaluatie te maken) (Sandberg \& Presser, 2015). Een narratief kan meerdere en zelfs contradictorische discoursen omvatten; de constructie ervan zal veeleer strategisch aangepast zijn aan de ontvanger, aan de verwachte vorm en conventies van de context. Narratieven zijn geen constructies van afzonderlijke indivi- 
duen en opereren niet in een sociaal vacuüm - narratieve criminologen benadrukken bijgevolg de culturele en structurele inbedding van narratieven (zie bijv. Fleetwoods (2016) bijdrage over narrative habitus; Copes' (2016) werk rond formula stories en culturele narratieven; publicaties over hegemoniale of masternarratieven en counternarratieven (Althoff et al., 2020); stellingen over ongelijke toegang tot narratieven (Presser \& Sandberg, 2015b)). Toch zijn de bijdragen die vanuit een narratief criminologische bril geschreven zijn in dat opzicht behoorlijk divers. Sommige positioneren zich uitdrukkelijk binnen de kritische criminologie en focussen op machtsverhoudingen vanuit een macro-sociologisch perspectief (Fleetwood, 2016; Petintseva, 2019; Presser \& Sandberg, 2019). Andere vertalen de premisse dat verhalen actie motiveren, inspireren en legitimeren naar etiologische probleemstellingen en hanteren daarbij een eerder objectivistisch criminaliteitsbegrip. Deze spagaat is zelfs merkbaar in de uiteenlopende definities die de grondleggers van het perspectief, Lois Presser en Sveinung Sandberg, in verschillende publicaties articuleren. Bijvoorbeeld:

'Narrative criminology views stories as criminogenic because they motivate and restrain crime and harm, and it studies, in detail, how this is done' (Sandberg 2016, p. 154).

In een andere publicatie zien we dan weer een eerder kritische invulling:

'We submit that narrative criminology is an apt and powerful framework for research in critical criminology because narrative criminology is fundamentally concerned with harm or resistance to harm, underscores collective involvement in the genesis of harm, illuminates the dynamism of harm and therefore the possibilities of resistance, and compels a reflexive stance on one's research' (Presser \& Sandberg, 2019, p. 131).

De etiologische insteek zorgde al voor heel wat discussies. Omdat de narratieve turn traag op gang kwam binnen de criminologie, weerklinkt vanuit ander disciplinair erfgoed bijvoorbeeld de kritiek dat de narratieve criminologie te veel zou vertrouwen op de first wave narratieve psychologie en een te prominente rol zou toebedelen aan narratieven in self-change. De constitutieve visie zou met andere woorden te rechtlijnig en causaal zijn (Laws, 2020). Ook in het voeren van onderzoek naar zelf-narratieven suggereert Laws (2020) dat narratieve criminologen onbewuste processen en theologische verhalen in hun beschouwing moeten meenemen (i.e. the experiencing self en the unconscious self, naast the reflexive self). Dit is tevens een belangrijk discussiepunt waar Alfredo Verde in zijn artikel 'Whose narratives? The Self as (also) an alien - for a complex concept of 'Self' in narrative criminology' in dit themanummer op ingaat. 


\section{Casestudies en 'recentere' shifts}

De narratieve criminologie is betrekkelijk nieuw; hoewel het nog wat voorbarig is om te spreken van 'klassiekers' en 'recente ontwikkelingen', tekenen zich toch duidelijk enkele trends af. Talrijke empirische (case)studies zijn gevoerd vanuit het narratief criminologisch perspectief, veelal met thema's als: narratieven van geweldplegers, desistance narratieven, verhalen van druggebruik (Sandberg, Tutenges \& Copes, 2015, O'Connor, 2015). Bijzondere aandacht is gegaan naar narratieve uitsluitingsmechanismen: (i) symbolic boundaries, en vooral de wijzen waarop mensen met behulp van narratieven gewenste identiteiten en referentiekaders creëren terwijl ze zich distantiëren van anderen (Copes, 2016); (ii) uitsluitingsmechanismen in de narratieven in gevangeniscontext (Ugelvik, 2015), (iii) gegenderde dynamieken van narratieven; i.e. de historisch contingente manieren waarop gender, sekse en/of seksualiteit narratieven worden vormgegeven, maar ook de theoretische brillen van waaruit ze worden benaderd (Fleetwood, 2015; Miller, Carbone-Lopez \& Gunderman, 2015).

In empirisch onderzoek vertrekt het gros van de narratief criminologische studies vanuit de individuele actie/omissie en de vraag waarom individuen regeloverschrijdend en/of schadelijk gedrag stellen, om dit vervolgens in een ruimere culturele context te kaderen. We zien echter ook groeiende aandacht voor mass harms. Bijvoorbeeld in Why We Harm theoriseerde Presser (2013) dat uiteenlopende vormen van massaschade (van milieudegradatie, vlees eten, tot verkrachting en genocide) aan hun basis drie vergelijkbare (narratieve) elementen hebben die een culturele logica volgen: othering, entitlement en inevitability. In dit themanummer wijdt Bas van Stokkom een uitgebreide bespreking aan Pressers benadering. Ook zien we de opkomst van perspectieven die zich richten op de analyse van publieke narratieven en maatschappelijke storytelling. Denk bijvoorbeeld aan mediaverhalen, narratieven van politici of professionals (Dollinger, 2020; Feilzer, 2009; Peelo \& Soothill, 2000). Publieke narratieven worden hier beschouwd als 'een toegang' tot criminaliteit en bestraffing voor het publiek, ze brengen een narratief kader over en geven betekenis aan wat er in het dagelijkse leven gebeurt. Mensen verwijzen immers naar beschikbare publieke verhalen en relateren hun zingeving aan actuele narratieven die bijvoorbeeld in de media aan bod komen (Feilzer, 2015)

Een belangrijke theoretische verschuiving vindt plaats met de ontwikkeling van ideeën en concepten van counternarratieven. Counternarratieven zijn van centraal belang voor een narratieve analyse van criminaliteit omdat de uiteenlopende contexten waarbinnen verhalen worden verteld in zekere zin conflict impliceren: wie een misdaadverhaal vertelt, moet het aanpassen aan de respectievelijke contexten en het relevante publiek, zodat het als overtuigend wordt aangezien. Verhalen bieden (alternatieve) manieren om een gebeurtenis te begrijpen, ons te overtuigen of om juist iets te ontkennen (Althoff et al., 2020). In deze processen maken we gebruik van cultureel beschikbare betekenissen en interpretaties. Door te focussen op contextuele en conflictueuze omstandigheden van verhalen, worden hegemoniale en subversieve dimensies zichtbaar (Poletta, 2006; Bamberg, 2008; Bamberg \& Wipff, 2020). 
Naast deze ontwikkelingen zien we een geleidelijk aan groeiende aandacht voor institutionele verhalen ofwel narrotologie van professionals in de sociale controle. In tegenstelling tot de vroegere eerder terloopse vermeldingen van de aanwezigheid van narratieven in de instellingen van de strafrechtsbedeling en sociale reactie in bredere zin (bijv. Maruna, 2015; Presser, 2010), gaan recent steeds meer narratieve criminologen empirisch onderzoek verrichten om narratieven geproduceerd in de institutionele contexten te ontrafelen (Kurtz \& Upton, 2017; Petintseva, 2018; Ugelvik, 2016; Verde et al., 2006). Deze onderzoekers werpen licht op de institutionele realiteit om vervolgens na te gaan hoe in specifieke cases en/of door individuele professionele actoren verhalen worden geproduceerd, hoe hiermee wordt omgegaan, hoe hegemoniale praktijken worden bestendigd of juist uitgedaagd. In die zin zien we de aandacht enigszins verschuiven van de psychosociale theorie naar de sociologie van de institutionele praktijk. Deze praktijk, en de verhalen die hierin worden geproduceerd, kenmerkt zich door specifieke culturele en institutionele conventies (in doelen, vorm, taalgebruik, logistiek, wettelijke omkadering, specifiek beleid). Desalniettemin is de sociale praktijk van vele instituties in belangrijke mate gebaseerd op verhalen en hun re-narratie in documenten en beslissingspraktijken. Narratieven zijn in die zin geenszins een (selectieve) representatie van de realiteit; ze zijn constitutief voor de institutionele trajecten en zijn bijgevolg performatief en materieel (Bacchi, 2009; Petintseva, 2018). Deze institutionele verhalen weerspiegelen bovendien de complexe aard van waarden, verwachtingspatronen, identiteiten, culturen (Sandberg, 2010) én machtsrelaties. Een interessant voorbeeld in dit opzicht is het werk van Bereswill en collega's (2020), die individuele dossiers binnen residentiële zorginstellingen onderzochten. Dossiers worden opgevat als krachtige artefacten die bepaalde acties binnen de instellingen creëren en motiveren. Dit onderzoek laat tevens zien in hoeverre individuele dossiers als narratieven kunnen worden geanalyseerd. De studie toont aan dat dergelijke dossiers prototypische masternarratieven bevatten waarin een 'afwijkend' subject wordt geconstrueerd. Hoewel institutionele dossiers binnen de perken van bureaucratische kaders en interacties moeten blijven, is er ruimte om te onderhandelen over sociale orde en sociale controle zonder dat dit ten koste gaat van de institutionele macht. De groeiende aandacht voor institutionele narratieven is niet alleen een thematische verbreding van de narratieve criminologie, het laat de onderzoekers nog meer toe om de sociale, politieke en culturele context te belichten (daar waar gebrekkige maatschappelijke contextualisering een van de voornaamste kritieken is op de eerdere narratief-psychologische oriëntatie van zelfnarratieven (Aspden \& Hayward, 2015)).

Nog een andere recente ontwikkeling is de vruchtbare kruisbestuiving met narratieve victimologie (Clark, 2020; Pemberton, Aarten \& Mulder, 2018). Volgens vertegenwoordigers van de narratieve victimologie heeft het narratieve perspectief een enorm potentieel om de verschillende manieren waarop slachtofferervaringen worden ingebed in levensverhalen te analyseren. Voor slachtoffers is het 'eigenaarschap' van hun narratieven een belangrijk element van hun ervaring, en om secundaire victimisatie te voorkomen (Pemberton, Aarten \& Mulder 2018). 
Christies (1977) idee van conflicts as property wordt hier toegepast op het slachtofferperspectief. De onteigening van conflicten als gevolg van een strafrechtelijke behandeling berooft de betrokkenen van de mogelijkheid om hun eigen vormen van verwerking te ontwikkelen en te beoefenen. Ook Walklate en collega's (2018) wijzen op het belang van verhalen voor de victimologie om te begrijpen hoe het komt dat sommige mensen een slachtofferidentiteit omarmen en anderen niet. Volgens deze auteurs moeten dergelijke verhalen de basis vormen voor beleid. Wat narratieve criminologie betreft, leverde Antony Pemberton een belangrijke 'brede' bijdrage aan dit themanummer, getiteld 'Alsof slachtofferschap een verhaal is: de narratieve victimologie en haar grenzen'.

Ten slotte: epistemologisch en methodologisch verlaat het narratief perspectief stilaan de nauwe invulling van narratief als noodzakelijk talig. Zo zien we groeiende onderzoeksinteresse in het visuele aspect ervan (Carrabine, 2016) en in voorwerpen (Ugelvik, 2019). Dit is relatief nieuw voor criminologie maar niet voor literary theorists, die al lang verschillende culturele artefacten als 'tekst' interpreteren (McGregor, 2020). Een interessant voorbeeld is de museale etnografie van Thurston $(2017,2020)$ in de Texas Prison Museum, waarin zij collectieve verhalen over de doodstraf reconstrueert en onderzoekt hoe musea culturele betekenissen van misdaad en straf produceren. In haar analyse belicht ze het complexe samenspel tussen dominante narratieven over zware straffen en de counternarratieven over de doodstraf. De auteur beschouwt museums als 'storied spaces' die krachtige verhalen over criminaliteit leveren, maar ook ruimte bieden om concepten zoals rechtvaardigheid en orde te problematiseren.

\section{Een veelbelovend open einde}

Op basis van deze beschouwing in bird's-eye view kunnen we stellen dat het narratief criminologisch netwerk in relatief korte tijd bijzonder ondernemend en actief is geworden: na het basisartikel van Presser (2009) in Theoretical Criminology, volgden behoorlijk wat invloedrijke boeken, artikelen en verzamelwerken, zoals bijvoorbeeld Narrative Criminology, Understanding Stories of Crime (2015), The Emerald Handbook of Narrative Criminology (2019), en een themanummer van Crime Media Culture (2016). Narratieve criminologen organiseerden eveneens drie internationale symposia en ze zijn zichtbaar aanwezig binnen grootschalige netwerken zoals de European Society of Criminology en de American Society of Criminology. Het is een dynamische (alweer nieuwe) criminologie die erin slaagde om op korte termijn originele inzichten, boeiende discussies en talrijke toepassingen te genereren. In het Nederlandstalig taalgebied horen we vooralsnog relatief weinig over narratieve criminologie. Het doel van dit themanummer is om de ontwikkelingen en discussies binnen de narratieve criminologie te duiden en vooral mee vorm te geven. Parallel aan andere analyses over de toekomst van de stroming (Presser \& Sandberg, 2015b; Fleetwood et al., 2019) willen we reflecteren over de vraag waar nog relevante theoretische en empirische pistes liggen die verdere uitdieping behoeven. Dit is ook meteen de uitdaging die de auteurs van de 
artikelen in dit themanummer zijn aangegaan: theoretisch of methodologisch vernieuwende bijdragen aanleveren over de toekomst van narratieve criminologie, in plaats van een reeks casestudies belichten vanuit de bestaande inzichten van het narratief criminologisch perspectief. We zien vooral dat de auteurs belangrijke bruggen bouwen.

Avi Brisman heeft onze uitnodiging aanvaard om de relatie tussen narratieve en culturele criminologie verder te verkennen (zie ook Aspden \& Hayward, 2015; Mills \& Fleetwood, 2019). Met zijn Cultural criminology and narrative criminology's shared interests: More than just criminological verstehen vult hij vooral Mills' en Fleetwoods (2019) artikel aan over criminologisch Verstehen (verschenen in het recente themanummer van ToCC (2019, nr. 3, p. 30-47), getiteld 'Betrokken onderzoeksmethoden'). Brisman vestigt vooral de aandacht op de analyses van media looping en cycles of storytelling practice and lived experiences.

Alfredo Verde levert met zijn Whose narratives? The Self as (also) an alien for a complex concept of 'Self' in narrative criminology een fundamentele bijdrage over het concept 'the Self' in de narratieve criminologie. Zijn artikel haakt aan bij de eerder vermelde recente discussie opgestart door Ben Laws (2020) in Theoretical Criminology. Verdes stuk is een brede en minutieuze uiteenrafeling van de verschillende invullingen van het complexe concept. Verde voert aan dat Laws' kritiek slechts ten dele standhoudt en stelt een meer complexe en dynamische definitie van 'the Self' in de narratieve criminologie voorop.

Antony Pemberton breekt een lans voor narratieve victimologie in zijn artikel Alsof slachtofferschap een verhaal is: de narratieve victimologie en haar grenzen. Ook dit is een brede synthese en reflectie, waarbij Pemberton verschillende kernonderwerpen in de narratieve victimologie bespreekt. Het artikel gaat met name over de narratieve impact van slachtofferschap, het belang van verhalen in de nasleep van slachtofferschap, het belang van narratieve perspectieven als het aankomt op de positie van slachtoffers in rechtsprocessen, evenals de verhouding tussen het verhaal van het slachtoffer en dat van anderen (cf. secundaire victimisatie). Pemberton introduceert tevens een kritische noot door te wijzen op de limieten van de narratieve victimologie.

In zijn artikel Exploring narrative, convictions and autoethnography as a convict criminologist legt Rod Earle links naar convict criminology. De connectie ziet hij vooral in het centraal stellen van eerstepersoonervaringen en -narratieven. Epistemologisch slaat Earle bruggen tussen narratieve en postkoloniale perspectieven in de criminologie. In het artikel maakt hij ook een methodologisch punt door de meerwaarde te belichten van het gebruik van (auto-etnografische) vignetten om ervaringen te communiceren.

In haar artikel Narratieve criminologie meets participatief actieonderzoek: Een reflectie over epistemologische mogelijkheden en uitdagingen bespreekt Michelle Van Impe een vruchtbare kruisbestuiving tussen narratieve criminologie en participatief actieonderzoek (participative action research (PAR)). 
De inzichtrijke reflectie over de relatie tussen PAR en de narratieve criminologie voert Van Impe op basis van haar studie naar stigma bij druggebruikers. Ze ziet uitdagingen bij de merge van de twee benaderingen (bijv. als het aankomt op de rol van de onderzoeker) maar voert overtuigend aan dat wanneer PAR en narratief onderzoek elkaar ontmoeten, er (meer) ruimte ontstaat voor het beoefenen van kritische, ethische en sociaal geëngageerde narratieve criminologie. Narratieve criminologie op haar beurt versterkt PAR door haar sterke analytische aandacht voor discursieve machtsstructuren, ook als het aankomt op het begrijpen van de relatie tussen narratieven en actie.

Merlijn van Hulst levert een rijk methodologisch stuk met zijn Verhalen in interviews: Kritisch met de narratieve criminologie meekijken. Van Hulst knoopt de discussie aan met auteurs van ruimere methodologische literatuur over interviews. In unisono met de grondleggers van de narratieve criminologie en vele constructivistische onderzoekers ziet Merlijn van Hulst interviewnarratieven als een specifiek discursief handelen (en dus niet als een feitelijke weergave van het perspectief van de participanten). Het artikel levert echter ook 'kritiek op de interviewkritiek', aldus de auteur. Aan het einde van het stuk biedt hij waardevolle en tastbare manieren om interviewverhalen te verrijken door middel van aanvullende vertellingen in interviews.

Het essay van Bas van Stokkom biedt ons een doorwrocht overzicht van het werk van Lois Presser, vooral als het aankomt op narratieve legitimering van massale schade. Hij belicht hiermee de eerder kritisch criminologische insteek van een van de grondleggers van de narratieve criminologie.

Ook in dit themanummer vinden de lezers een in memoriam of, beter, persoonlijke herinneringen van Richard Staring aan Lodewijk Brunt, die in oktober 2020 overleed.

\section{Literatuur}

Althoff, M., B. Dollinger, \& H. Schmidt (2020). Fighting for the 'right' narrative. In: M. Althoff, B. Dollinger \& H. Schmidt (eds.), Conflicting narratives of Crime and Punishment (p. 1-20). London: Palgrave.

Aspden, K. \& K. Hayward (2015). Narrative criminology and cultural criminology: Shared biographies, different lives? In: L. Presser \& S. Sandberg (eds.), Narrative criminology. Understanding stories of crime (p. 235-259). New York: New York University Press.

Bacchi, C. (2009). Analysing policy: What's the problem represented to be? Frenchs Forest: Pearson.

Bamberg, M. (2008). Master narrative. In: D. Herman, M. Jahn \& M.-L. Ryan (eds.), Routledge encyclopedia of narrative theory (p. 287-288). London: Routledge.

Bamberg M. \& Z. Wipff (2020). Counter-narratives of crime and punishment. In: M. Althoff, B. Dollinger \& H. Schmidt (eds.), Conflicting narratives of Crime and Punishment (p. 23-41). London: Palgrave. 
Bereswill, M., H. Buhr \& P. Müller-Behme (2020). Files as prototypical master narratives. In: M. Althoff, B. Dollinger \& H. Schmidt (eds.), Conflicting narratives of Crime and Punishment (p. 201-218). London: Palgrave.

Carrabine, E. (2016). Picture this: Criminology, image and narrative. Crime, Media, Culture, 12(2), 253-270.

Christie, N. (1977). Conflicts as property. The British Journal of Criminology, 17(1), 1-15.

Clark, J.N. (2020). Storytelling, resilience and transitional justice: Reversing narrative social bulimia. Theoretical Criminology, online ahead of print: 1362480620933230.

Copes, H. (2016). A narrative approach to studying symbolic boundaries among drug users: A qualitative meta-synthesis. Crime, Media, Culture, 12(2), 193-213.

Crewe, D. \& R. Lippens (2009). Existentialist criminology. London: Routledge.

Dollinger, B. (2020). Changing narratives of youth crime. London: Routledge.

Ewick, P. \& S.S. Silbey (1995). Subversive stories and hegemonic tales: Toward a sociology of narrative. Law and Society Review 29(2), 197-226.

Feilzer, M. (2009). The importance of telling a good story: An experiment in public criminology. The Howard Journal, 48(5), 472-484. doi: 10.1111/j.1468-2311.2009.00589.x.

Feilzer, M.Y. (2015). Public knowledge of crime and criminal justice. The neglected role of public narratives. In Oxford Handbooks Online. doi: 10.1093/oxfordhb/ 9780199935383.013.104.

Ferrell, J., Hayward, K. \& Young, J. (2015). Cultural criminology: An invitation (2nd edition). London: Sage.

Fleetwood, J. (2015). In search of respectability: Narrative practice in a women's prison in Quito, Ecuador. In L. Presser \& S. Sandberg (eds.), Narrative criminology: Understanding stories of crime (p. 42-68). New York, NY: New York University Press.

Fleetwood, J. (2016). Narrative habitus: Thinking through structure/agency in the narratives of offenders. Crime, Media, Culture, 12(2), 173-192.

Foqué, R. \& J. 't Hart (1990). Instrumentaliteit en rechtsbescherming: Grondslagen van een strafrechtelijke waardendiscussie. Arnhem/Antwerpen: Gouda Quint.

Henry, S. \& D. Milovanovic (1997). Constitutive criminology. The maturation of critical theory. In D. Milovanovic (Ed.), Postmodern criminology (p. 77-92). New York: Taylor \& Francis.

Kurtz, D. L. \& Upton (2017). War stories and occupying soldiers: A narrative approach to understanding police culture and community conflict. Critical Criminology, 25, 539-558.

Laws, B. (2020). Reimaging 'the Self' in Criminology: Transcendence, Unconscious States and the Limits of Narrative Criminology. Theoretical Criminology, online ahead of print: 1362480620919102.

Maruna, S. (2001). Making good: How ex-convicts reform and rebuild their lives. Washington, DC: American Psychological Association.

Maruna, S. (2015). Narrative criminology as the new mainstream. In: L. Presser \& S. Sandberg (eds.), Narrative criminology. Understanding stories of crime (p. vii-xi). New York: New York University Press.

McGregor, R. (2020). Review: The Emerald handbook of narrative criminology. Critical Criminology, 28, 155-158.

Miller, J., K. Carbone-Lopez \& M.V. Gunderman (2015). Gendered narratives of self, addiction, and recovery among women metamphetamine users. In L. Presser \& S. Sandberg (eds.), Narrative criminology: Understanding stories of crime (p. 69-95). New York: New York University Press.

Mills, M.F. \& J. Fleetwood (2020). Prepping and verstehen: A narrative criminological perspective. Tijdschrift over Cultuur \& Criminaliteit, 9(3), 30-47. 
O'Connor, P.E. (2015). Telling moments: Narrative hot spots in accounts of criminal acts. In: L. Presser \& S. Sandberg (eds.), Narrative criminology. Understanding stories of crime (p. 174-205). New York: New York University Press.

Peelo, M. \& K. Soothill (2000). The place of public narratives in reproducing social order. Theoretical Criminology, 4, 131-148.

Pemberton, A., P.G.M. Aarten \& E. Mulder (2018). Stories as property: Narrative ownership as a key concept in victims' experiences with criminal justice. Criminology \& Criminal Justice, 19(4), 404-420.

Petintseva, O. (2019). Reflections after 'Socrates light': Eliciting and countering narratives of youth justice officials. In J. Fleetwood, L. Presser, S. Sandberg \& T. Ugelvik (eds.), Emerald handbook of narrative criminology (p. 87-108). London: Emerald.

Petintseva, O. (2015). Boekbespreking: Cultural Criminology. An Invitation (2de ed.). Panopticon, 36(5), 489-493.

Polletta, F. (2006). It was like a fever: Storytelling in protest and politics. Chicago IL.: University of Chicago Press.

Presser, L. (2009). The narratives of offenders. Theoretical Criminology, 13(2), 177-200.

Presser, L. (2010). Collecting and analyzing the stories of offenders. Journal of Criminal Justice Education, 21(4), 431-446.

Presser, L. (2013). Why we harm. New Brunswick, NJ: Rutgers University Press.

Presser, L. (2016). Criminology and the narrative turn. Crime Media Culture 12(2), 137-151.

Presser, L. (2018). Inside story. How narratives drive mass harm. California: University of California Press.

Presser, L. \& Sandberg, S. (2015a). Introduction. What is the story? In: L. Presser \& S. Sandberg (eds.), Narrative criminology. Understanding stories of crime (p. 1-22). New York, NY: NYU Press.

Presser \& Sandberg (2015b). Conclusion: Where to now? In: L. Presser \& S. Sandberg (eds.), Narrative criminology. Understanding stories of crime (p. 287-300). New York, NY: NYU Press.

Presser, L. \& Sandberg, S. (2019). Narrative criminology as critical criminology. Critical Criminology: An International Journal 27(1), 131-143.

Sandberg, S. (2016). The importance of stories untold: Life-story, event-story and trope. Crime, Media, Culture, 12, 153-171.

Sandberg, S. (2010). What can 'lies' tell us about life? Notes towards a framework of narrative criminology. Journal of Criminal Justice Education, 21(4), 447-465.

Sandberg, S., Tutenges, S. \& Copes, H. (2015). Stories of violence: A narrative criminological study of ambiguity. British Journal of Criminology, 55(6), 1168-1186.

Sandberg, S. \& Ugelvik, T. (2016). The past, present, and future of narrative criminology: A review and an invitation. Crime Media Culture, 12(2), 129-136.

Stein, D. (2020). Conflicting counternarratives of crime and justice in US superhero comics. In M. Althoff, Dollinger, B. \& Schmidt, H. (eds.) Conflicting narratives of Crime and Punishment (p. 139-160). London: Palgrave.

Van Swaaningen, R. (1995). Critical criminology. Visions from Europe. London: Sage.

Sykes, G. M. \& Matza, D. (1957). Techniques of neutralization: A theory of delinquency. American Sociological Review, 22(6), 664-670.

Thurston, H. (2017). Museum ethnography: Researching punishment museums as environments of narrativity. Methodological Innovations Online, 10, 1-12.

Thurston, H. (2020). Popular and visual narratives of punishment in museum settings. In M. Althoff, Dollinger, B. \& Schmidt, H. (eds.) Conflicting narratives of Crime and Punishment (p. 113-137). London: Palgrave. 
Ugelvik, T. (2015). The rapist and the proper criminal. In L. Presser \& S. Sandberg (eds.), Narrative criminology. Understanding stories of crime (p. 23-41). New York: New York University Press.

Ugelvik, T. (2016). Techniques of legitimation: The narrative construction of legitimacy among immigration detention officers. Crime, Media, Culture, 12(2), 215-232.

Ugelvik, T. (2019). The tales things tell: Narrative analysis, materiality and my wife's old Nazi rifle. In J. Fleetwood, L. Presser, S. Sandberg \& T. Ugelvik (eds.). The Emerald handbook of narrative criminology (p. 217-233). Bingley: Emerald.

Verde, A., Angelini, F., Boverini, S. \& Marajana, M. (2006). The narrative structure of psychiatric reports. International Journal of Law and Psychiatry, 29(1), 1-12.

Walklate, S., J.M. Maher, J. McCulloch et al. (2018). Victim stories and victim policy: Is there a case for a narrative victimology? Crime Media Culture, 15(2), 199-215. 